\title{
Gas-Liquid-Solid Fluidized Bed Simulation by Computational Fluid Dynamics
}

\author{
S.N. Saha \\ Professor, Dept. of Chemical Engg, \\ Guru GhasidasVishwavidyalaya (Central \\ University), Bilaspur (C.G.), India
}

\section{G.P. Dewangan}

\author{
Assistant Professor, Dept. of Chemical Engg., \\ Guru GhasidasVishwavidyalaya (Central \\ University), Bilaspur (C.G.), India
}

\section{R. Gadhewal}

SRF, IIT, Mandi, Himachal Pradesh, India

\begin{abstract}
Gas-liquid-solid fluidized bed technique has emerged recently as one of the most promising one for three phase operations involved in chemical, biochemical, petrochemical, pharmaceutical processing industries. Out of the fundamental characteristics of a three-phase fluidized bed, the gas hold up and liquid hold up behaviours have been studied extensively. Considering the various researchers' findings, keeping in view of the comparison, these two characteristics have been studiedfor analysing the performance of a three-phase fluidized bed. In the present work STAR-CCM+ has been used to study gas-liquid-solid fluidization for CFD simulation has been carried out for a column having the dimension of $1.88 \mathrm{~m}$ height and $0.1 \mathrm{~m}$ diameter bed comprising glass bead as solid particle of size $2.18 \mathrm{~mm}$. The present paper deals with the CFD analysis of these two characteristics using CD-Adapco engineering commercial STAR-CCM+CFD software for generation of a $3 D$ fine grid. In the present work air has been considered as the gas, water as the liquid to be passing through the base of the fluidized bed with different velocities.
\end{abstract}

Keywords: Three phase fluidization holdup, CFD, Euler-Euler approach, Modelling and Simulation, Contours

\section{INTRODUCTION}

The variables affecting the quality of three phase like liquid-gas-solid fluidization are fluid inlet and flow rate, bed height, particle size, densities of all the three phases, bed internals for prevention of the bubble size growth and lateral movement of fluid and solid, formation of slug and elutriation of fines, gas hold up, bed expansion. For design and development of three phase fluidized bed reactor, knowledge of hydrodynamic parameter like gas holdup defined as the volume fraction of gas phase in the reactor is the most essential key parameterrequirement justifying the present study of the effect of important operating variables. This key parameter for characterization of the complex hydrodynamicsof the three phase fluidized bed depends on inter alia gas velocity, superficial liquid velocity, fluidized bed column height and diameter, physical properties of gas liquid and solid. There are various research work undertaken in the area of fluidization engineering and its applications (1-15) since last four decades. The present paper deals with simulation of the variables gas hold up and liquid hold up and their effects on three phase fluidization.There are typical examples of this three phase fluidized bed principle like hydrogenation and hydrosulphurisation of residual oil from coal liquefaction, coking of petroleum residues flue gas desulphurisation, bio-oxidation process in aerobic waste water treatment, oxidation of naphthalene to pthalic anhydride, methanol and ethanol production etc. The success of the complex system of three phase fluidized bed depends mainly on the effective contact of every phase with the other one.The Computational Fluid Dynamics (CFD) tool used for simulation in the present work for better understanding, designing and development of multiphase in engineering application like gas-liquid-solid phase fluidized bed has got various advantages like (i) because of flexibility of changing design parameters, engineers can try more alternative designs; (ii) more suitable for trouble shooting; (iii) information can be collected on the flow regimes wherein the measurements are even not possible to be made. CFD involves in numerical solution of the fundamental nonlinear differential equations describing fluid flow Navier-Stokes equations with pre-set boundary conditions. Usually CFD code involves mainly three elements like pre-processing, post-processing and solver. Pre-processing element involves the steps of defining the 
geometry of the region for computational domain, generating grids for subdivision of the domain and specifying appropriate boundary and continuum conditions at cells. The solver element performs the flow calculation with approximation of unknown flow variables, discretization by substitution of approximation on the governing flow equation and eventually solving the equations. There are three discretization methods in the Computational Fluid Dynamics, namely Finite Difference, Finite Volume and Finite Element Method. The post-processing leads to the result and interpretation.The significant outcomes of post-processing are domain geometry, grid display, contour plot of the properties, animation, surface plot, plot convergence.There may be two approaches for multiphase flow modelling. One is Euler-Lagrangeand the other isEuler-Eulerapproach.The Euler-Lagrange approach is applicable to continuous dispersed system referred to usually a discrete particle or particle transport model providing complete information on behaviour and residence time of individual particles. The Euler-Euler approach is mostly applicable to multiphase flows incorporating the volume fraction concept assuming it to be continuous function of space and time whose sum equals to be unity. There are three Euler-Euler Multiphase models namely Volume of Fluid, Mixture and Eulerian model. Various models have been resorted to by various researchers (1-15) as per convenience of the validity of their research experimental systems.

\section{Computational Modelling and Simulation of Three Phase Fluidized Bed}

The transport equations for momentum and continuity have been solved for all the phases of gas, liquid and solid phase. The equations for the inter phases are linked together through the drag law. The solid phase has got some additional equations to be solved for the kinetic, collisional and frictional regime fundamentally based on the kinetic theory of granular flow.

\subsection{Continuity Equation}

The continuity equation for each phase is as follows as there is no mass transfer between the phases:

$\frac{\partial}{\partial t}\left(\varepsilon_{g} \rho_{g}\right)+\nabla \cdot\left(\varepsilon_{g} \rho_{g} \overrightarrow{V_{g}}\right)=0$

$\frac{\partial}{\partial t}\left(\varepsilon_{s} \rho_{s}\right)+\nabla \cdot\left(\varepsilon_{s} \rho_{s} \overrightarrow{V_{S}}\right)=0$

$\frac{\partial}{\partial t}\left(\varepsilon_{l} \rho_{l}\right)+\nabla \cdot\left(\varepsilon_{l} \rho_{l} \overrightarrow{V_{l}}\right)=0$

Since the total volume fraction has to be equal to unity,

$\varepsilon_{g}+\varepsilon_{s}+\varepsilon_{l}=1$

\subsection{Momentum Equation of Gas Phase}

In the present problem the virtual mass force and lift forces have been ignored.

The momentum equation for gas phase is:

$\frac{\partial}{\partial t}\left(\varepsilon_{g} \rho_{g} \vec{V}_{g}\right)+\nabla \cdot\left(\varepsilon_{g} \rho_{g} \vec{V}_{g} \vec{V}_{g}\right)=\nabla \cdot \overline{\bar{\tau}}_{g}-\varepsilon_{g} \nabla P+\varepsilon_{g} \rho_{g} g+\beta_{g s}\left(\vec{V}_{s}-\vec{V}_{g}\right)$

The stress tensor $\overline{\bar{\tau}}_{\mathrm{g}}$ is computed by the following equation:

$\overline{\bar{\tau}}_{g}=\varepsilon_{g} \mu_{g}\left(\nabla \vec{V}_{g}+\left(\nabla \vec{V}_{g}\right)^{T}\right)+\varepsilon_{g}\left(\lambda_{g}+\frac{2}{3} \mu_{g}\right) \nabla \cdot \vec{V}_{g} \overline{\bar{I}}$

2.3. Momentum Equation of Solid Phase

Assuming no virtual mass and lift force, the solid phase momentum equation is established as:

$\frac{\partial}{\partial t}\left(\varepsilon_{s} \rho_{s} \vec{V}_{s}\right)+\nabla \cdot\left(\varepsilon_{s} \rho_{s} \vec{V}_{s} \vec{V}_{s}\right)=\nabla \cdot \overline{\bar{\tau}}_{s}-\nabla P_{s}-\varepsilon_{s} \nabla P+\varepsilon_{s} \rho_{s} g+\beta_{g s}\left(\vec{V}_{s}-\vec{V}_{g}\right)$

From the kinetic theory of granular flow the solid pressure is manipulated.

\subsection{Momentum Equation for Liquid Phase}

The established mathematical expression for momentum equation for liquid phase is as follows:

$\frac{\partial}{\partial t}\left(\varepsilon_{l} \rho_{l} \vec{V}_{l}\right)+\nabla \cdot\left(\varepsilon_{l} \rho_{l} \vec{V}_{l} \vec{V}_{l}\right)=\nabla \cdot \overline{\bar{\tau}}_{l}-\nabla P_{l}-\varepsilon_{l} \nabla P+\varepsilon_{l} \rho_{l} g+\beta_{l s}\left(\vec{V}_{s}-\vec{V}_{l}\right)$

\subsection{Kinetic Theory of Granular Flow}

Taking local dissipation of the granular energy into consideration, the granular temperature $\left(\Theta_{S}\right)$ is calculated from the following equation involving the factors owing to the collisions between particles. 
$\Theta_{S}=\left[\frac{-K_{1} \varepsilon_{s} \operatorname{tr}\left(\overline{\bar{\tau}}_{s}\right)+\sqrt{K_{1}^{2} t r^{2}\left(\overline{\bar{\tau}}_{s}\right) \varepsilon_{s}^{2}+4 K_{4} \varepsilon_{S}\left[K_{2} t r^{2}\left(\overline{\bar{\tau}}_{s}\right)+2 K_{3} \operatorname{tr}\left(\overline{\bar{\tau}}_{s}^{2}\right)\right]}}{2 \varepsilon_{s} K_{4}}\right]^{2}$

where, $\operatorname{tr}\left(\overline{\bar{\tau}}_{S}\right)$ is the stress tensor and the K's are defined as:

$$
\begin{aligned}
& K_{1}=2(1+e) \rho_{s} g_{0} \\
& K_{2}=\frac{4}{3 \sqrt{\pi}} d_{s} \rho_{s}(1+e) \varepsilon_{s} g_{o}-\frac{2}{3} K_{3} \\
& K_{3}=\frac{d_{s} \rho_{s}}{2}\left(\frac{\sqrt{\pi}}{3(3-e)}\left[1+\frac{2}{5}(1+e)(3 e-1) \varepsilon_{s} g_{o}\right]+\frac{8 \varepsilon_{s}}{5 \sqrt{\pi}} g_{o}(1+e)\right) \\
& K_{4}=\frac{12\left(1-e^{2}\right) \rho_{s} g_{0}}{d_{s} \sqrt{\pi}} \\
& P_{k}=\rho_{s} \varepsilon_{s} \theta_{s} \\
& P_{c}=2 g_{0} \rho_{s} \varepsilon_{s}^{2} \theta_{s}(1+e) \\
& \mu_{c}=\frac{4}{5} \varepsilon_{s} \rho_{s} d_{s}(1+e) \sqrt{\frac{\Theta_{s}}{\pi}} \\
& \mu_{k}=\frac{2 \mu_{d i l}}{g_{0}(1+e)}\left[1+\frac{4}{5}(1+e) \varepsilon_{s} g_{0}\right]^{2} \\
& \mu_{d i l}=\frac{5 \sqrt{\pi}}{96}\left(\varepsilon_{s} \rho_{s}\right)\left(\frac{d_{s}}{\varepsilon_{s}}\right) \sqrt{\Theta_{s}}
\end{aligned}
$$

\subsection{Schaeffer Friction Model}

This model equation is valid for the regions where the contact between the particles is continuous and the volume fraction of the particle exceeds a set value of a certain maximum packing limit. The following equations help in modelling the frictional pressure.

$P_{f}= \begin{cases}10^{25}\left(\varepsilon_{s}-\varepsilon_{s}^{\max }\right)^{10}, & \varepsilon_{s}>\varepsilon_{s}^{\max } \\ 0 & \varepsilon_{s} \leq \varepsilon_{s}^{\max }\end{cases}$

$\mu_{f}=\left\{\begin{array}{c}\min \left(\frac{P_{f} \sin (\phi)}{\sqrt{4 I_{2 D}}}, \mu_{m}^{\max }\right) \\ \varepsilon_{s} \leq \varepsilon_{s}^{\max }\end{array}, \varepsilon_{s}>\varepsilon_{s}^{\max }\right.$

and $\quad \mu_{m}^{\max }=1000 P$

$\mathrm{I}_{2 \mathrm{D}}=\frac{1}{6}\left[\left(D_{s 11}-D_{s 12}\right)^{2}+\left(D_{s 22}-D_{s 33}\right)^{2}+\left(D_{s 33}-D_{s 11}\right)^{2}\right]+D_{s 12}^{2}+D_{s 23}^{2}+D_{s 31}^{2}$

and

$D_{s i j}=\frac{1}{2}\left(\frac{\partial u_{s i}}{\partial x_{j}}+\frac{\partial u_{s i}}{\partial x_{i}}\right)$

As the solid pressure is the summation of frictional, kinetic and collision pressures,

$P_{s}=P_{f}+P_{k}+P_{c}$

As the viscosity for the solid is the summation of the contribution due to friction, kinetic and collision. $\mu_{s}=\mu_{f}+\mu_{k}+\mu_{c}$

\subsection{Drag Model}

The Gidaspow drag model dealing with the drag force involved in the inter phase interaction has been referred in the present paper. The relevant working equations are as follows:

$I_{g s}=\beta_{g s}\left(u_{g}-u_{s}\right)$

The inter phase drag coefficient $\beta_{g s}$ is

$\beta_{g s}=\frac{3}{4} C_{D} \frac{\varepsilon_{s} \varepsilon_{g} \rho_{g}\left|u_{g}-u_{s}\right|}{d_{s}} \varepsilon_{g}^{-2.65}$ for $\varepsilon_{g}>0.8$

The Drag Coefficient,

$\begin{array}{ll}C_{D}=\left\{\begin{array}{cr}\frac{24}{\varepsilon_{g} R e_{s}}\left[1+0.15\left(\varepsilon_{g} R e_{s}\right)^{0.687}\right], & R e_{s}<1000 \\ 0.44 & R e_{s}>1000\end{array}\right. \\ \beta_{g s}=150 \frac{\varepsilon_{s}^{2} \mu_{g}}{\varepsilon_{g} d_{s}^{2}}+1.75 \frac{\varepsilon_{s} \rho_{g}\left[u_{g}-u_{s}\right]}{d_{s}} & \text { for } \varepsilon_{g}<0.2\end{array}$ 


\subsection{Turbulence Model}

The continuous gaseous phase of air has been modelled with k- $\varepsilon$ turbulence and the dispersed phase of glass beads were modelled as laminar. The turbulence model for air used in the present work as gas phase was the standard k- $\varepsilon$ model with RANS. Turbulent intensity, turbulent velocity ratio and turbulent viscosity ratio have been kept as default values available in STAR-CCM+ software package.

\subsection{Solver and Discretization Scheme}

In order to compute the velocity fraction and volume fraction, preferably the second order discretization by substitution of approximation governing flow equation was employed. In case of second order scheme was found to be unstable, the velocity factor was changed to first order.

Square cell has been used in the domain with the refinement near the inlet of the fluidized bed distributor for taking the mesh into account.

Based on the bulk density, initial condition packing fraction of the bed has been selected setting the maximum packing fraction.

The top boundary condition of $0 \mathrm{~Pa}$ has been specified with the bottom boundary condition having been set as the velocity inlet. The superficial velocity has been kept consistent by extrapolating the granular temperature of the particles to the boundary from the first layer of cell. The side wall was treated as no-slip condition for the fluid phase whereas the particle phase was made as the slip boundary condition; accordingly, the shear stress for the particle phase was set to be 0 . Also at the outlet the volume fraction of air and particle were set to be equal to 1 and 0 respectively.

In terms of the post processing task the average pressure drop was taken as 5-15 sec with the data acquisition at each physical time step. After $5 \mathrm{sec}$ physical time the fluidized bed has been considered to have reached to the quasi-steady state which can be verified by the pressure-time plot. The total mass was manipulated as the summation of the product of volume fraction of particle in each cell, the volume of each cell and the density of the particle, called as slice to be multiplied by the factor in order to account for three dimensional set up.

The following figure 1 shows mesh by CFD used in all the simulated parameters given in the following table 1 .

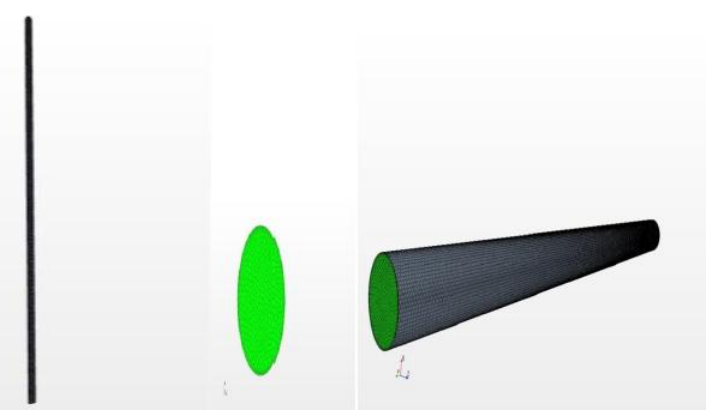

Figure1. Mesh created in STAR-CCM+ used in simulation.

Table1.Simulation Parameters

\begin{tabular}{|l|l|l|}
\hline \multicolumn{1}{|c|}{ Description } & \multicolumn{1}{c|}{ Value } & Comments \\
\hline Particle density & $2500 \mathrm{~kg} / \mathrm{m}^{3}$ & Glass beads \\
\hline Gas density & $1.2 \mathrm{~kg} / \mathrm{m}^{3}$ & Air at $20^{0} \mathrm{C}$ \\
\hline Liquid density & $1000 \mathrm{~kg} / \mathrm{m}^{3}$ & \\
\hline Mean particle diameter(d) & $2.18 \mathrm{~mm}$ & Uniform distribution \\
\hline Coefficient of restitution(e) & 0.9 & Range in literature \\
\hline Superficial gas velocity(U) & $0.025 \mathrm{~m} / \mathrm{s}-0.1 \mathrm{~m} / \mathrm{sec}$ & \\
\hline Bed width(D) & $0.1 \mathrm{~m}$ & Fixed value \\
\hline Free board height & $1.88 \mathrm{~m}$ & \\
\hline Static bed height(H) & $21.3 \mathrm{~cm}$ & \\
\hline Grid spacing & $0.1 \mathrm{~m}$ & Specified \\
\hline Time step & $0.001 \mathrm{~s}$ & Specified \\
\hline Cell count & 169149 & Fixed value \\
\hline Maximum physical time & $6 \mathrm{~s}$ & Specified \\
\hline
\end{tabular}




\section{RESULT AND DISCUSSION}

A gas-liquid-solid fluidized bed of diameter $0.1 \mathrm{~m}$ and height $1.88 \mathrm{~m}$ has been simulated using commercial CFD software package STAR-CCM+. Static bed of height $21.3 \mathrm{~cm}$ has been used for simulation. Diameter of the glass beads have been taken as $2.18 \mathrm{~mm}$.Inlet superficial velocity of gas has been taken for the present paper in a range of $0.025 \mathrm{~m} / \mathrm{s}$ to $0.1 \mathrm{~m} / \mathrm{s}$ whereas that of water has been taken in the range of $0.02 \mathrm{~m} / \mathrm{s}$ to $0.16 \mathrm{~m} / \mathrm{s}$. The simulation results obtained have been shown in the following figures $2-6$.

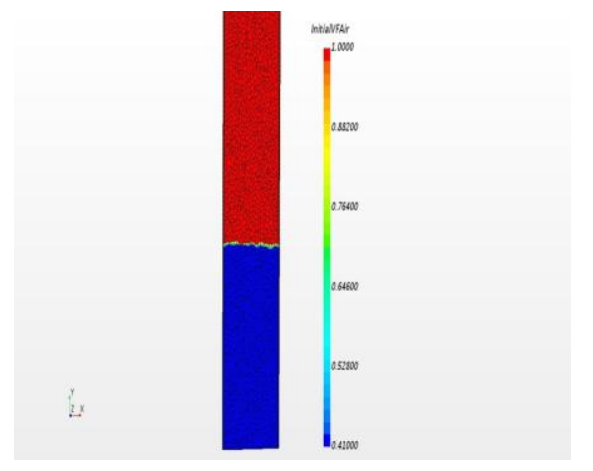

Fig2. Initial condition of volume fraction of solid particle in fluidized bed

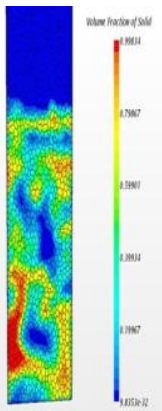

Fig4. Contours of volume fraction of solid at water velocity of $0.12 \mathrm{~m} / \mathrm{s}$ and air velocity of $0.0025 \mathrm{~m} / \mathrm{s}$ for initial static bed height of $0.213 \mathrm{~m}$.

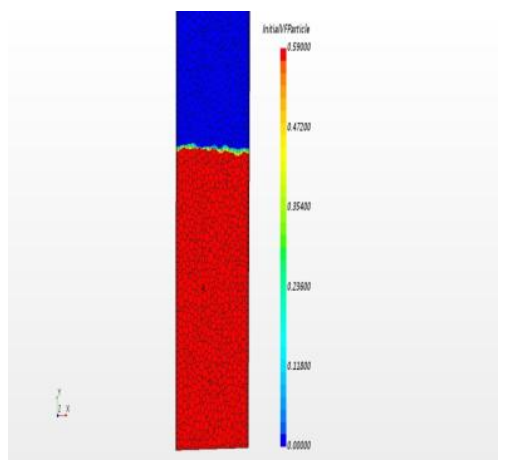

Fig3. Initial condition of volume fraction of air in fluidized bed

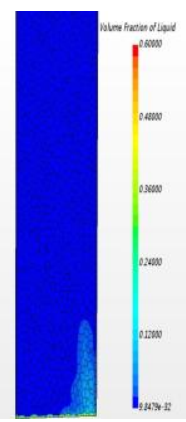

Fig5. Contours of volume fraction of liquid at water velocity of $0.12 \mathrm{~m} / \mathrm{s}$ and air velocity of $0.0025 \mathrm{~m} / \mathrm{s}$ for initial static bed height of $0.213 \mathrm{~m}$.

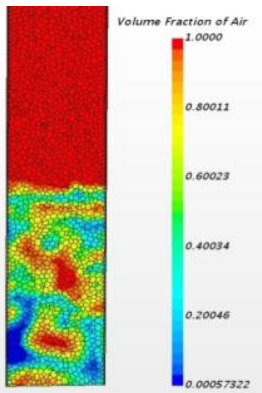

Fig6. Contours of volume fraction of air at water velocity of $0.12 \mathrm{~m} / \mathrm{s}$ and air velocity of $0.0025 \mathrm{~m} / \mathrm{s}$ for initial static bed height of $0.213 \mathrm{~m}$.

From the simulation a change in profile in the column is seen, but after some time no significant change is observed indicating the quasi steady state. The bed profile changed for the first 24 secs, after which there is no subsequent change in the bed profile, even till 26 to 30 seconds.

\subsection{Fluidized Bed Three Phases Hold Up}

From CFD simulation, the following figures represent the variation of gas holdup in the three-phase fluidized bed with superficial liquid velocity at constant gas velocity for $2.18 \mathrm{~mm}$ glass beads at static bed height $\mathrm{Hs}=0.213 \mathrm{~m}$. The gas velocity taken was in the range from $0.025 \mathrm{~m} / \mathrm{s}$ to $0.1 \mathrm{~m} / \mathrm{s}$ and the liquid velocities taken are in the range from $0.02 \mathrm{~m} / \mathrm{s}$ to $0.16 \mathrm{~m} / \mathrm{s}$. It is seen from the figure that with increasing liquid velocity, the gas holdup decreases. The result of decrease in gas holdup with liquid 
velocity may be explained as due to the fact that at higher liquid velocity the bubbles are fast driven by the liquid. The following figures 7-9 show the variation of solid, gas and liquid hold up respectively also with the same data of solid, liquid and gas phase.

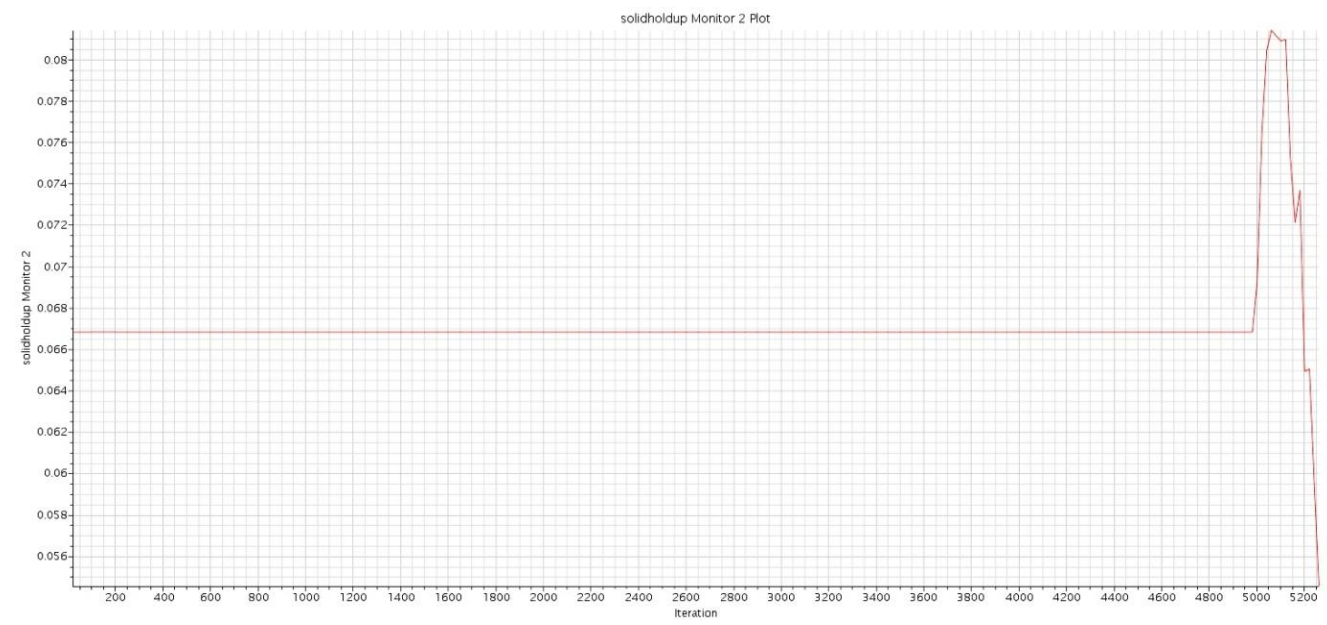

Fig7. Variation of solid holdup with liquid velocity at constant air velocity for $2.18 \mathrm{~mm}$ glass beads at Hs=0.213.

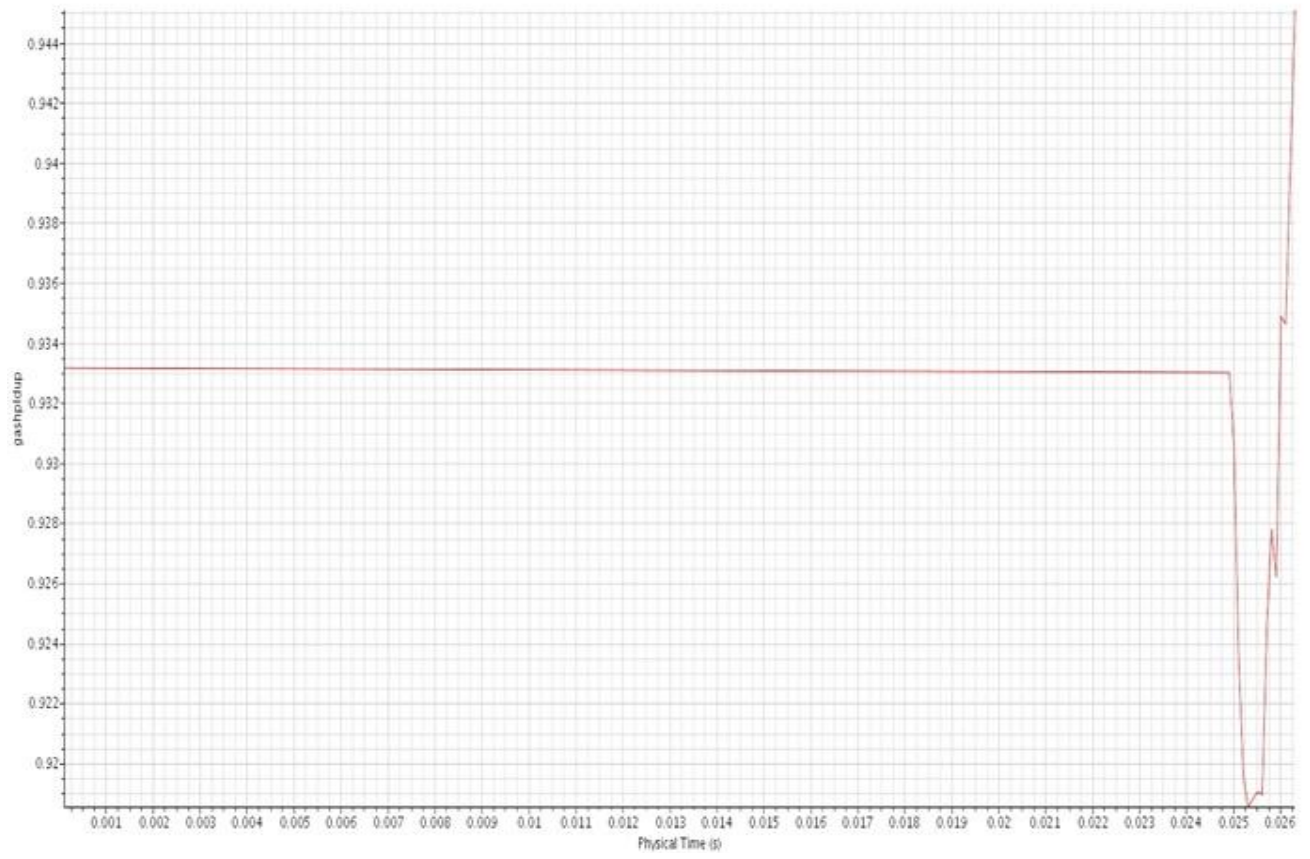

Fig8. Variation of gas holdup with liquid velocity at constant air velocity for $2.18 \mathrm{~mm}$ glass beads at Hs=0.213

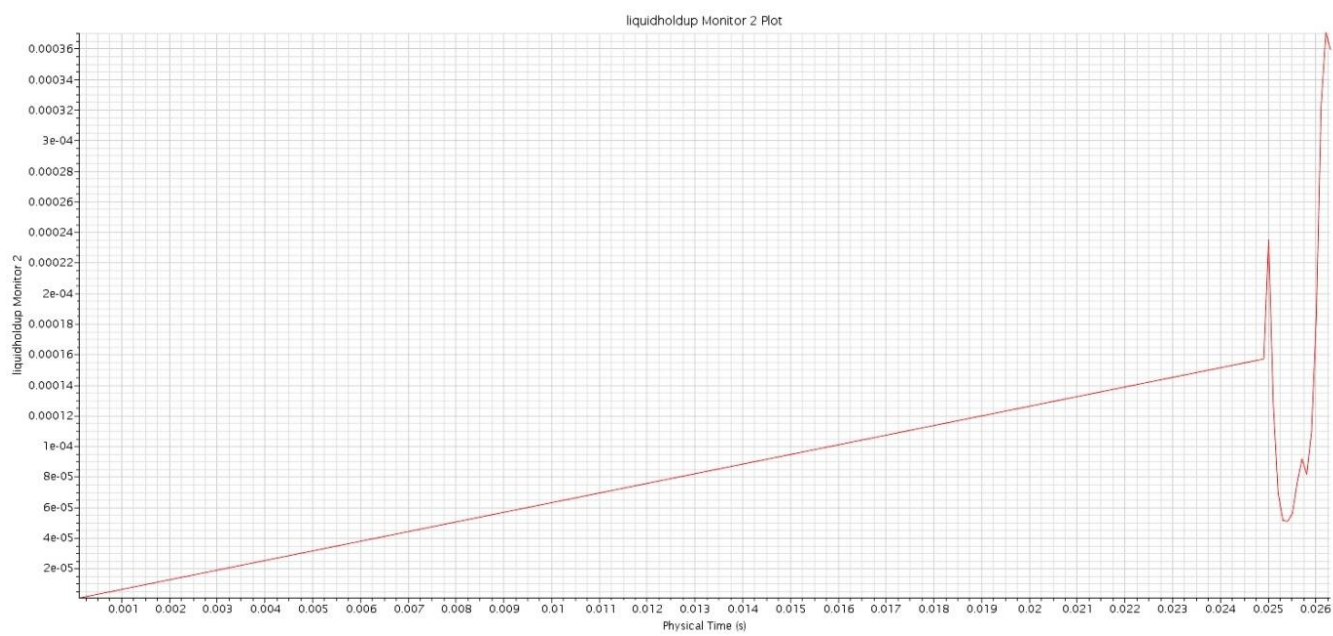

Fig9. Variation of liquid holdup with liquid velocity at constant air velocity for $2.18 \mathrm{~mm}$ glass beads at $H s=0.213$. 


\section{CONCLUSION}

Gas holdup has been found as more in fluidized part of the bed as depicted by the contours for airwith the consistency of increasing liquid velocity, the gas holdup decreases.Contour of volume fraction of water shows that the volume fraction of water is less in fluidized part of the column in comparison to the rest part. Trends of gas holdup vs. inlet air velocity shows that gas holdup increases with increase in air velocity valid at constant water velocity. Trends of gas holdup vs. inlet water velocity show that gas holdup decreases with the increase in inlet water velocity at constant air velocity. Liquid hold up increasing with inlet liquid velocity, was agreed with the findings of other researchers as high as for smaller solid particle size as compared with the larger particle sizes.Volume fraction of gas, liquid and solid with different bed height along radial direction shows in agreement of the findings of the literature that there is no variation in the volume fractions along the radius.It is concluded from the validation that Eulerian-Eulerian approach using the CFD software package STAR-CCM+ reported in the present paper is capable of predicting the overall performance of the gas-liquid-sold fluidized bed.

\section{REFERENCES}

[1] Saha, S.N. and Chanda, B.C. "Heat Transfer Study of Fluidised Bed Gas Combustion", Ind.Chem.Engr. JI.,Vol 14.No. 2, 1982.

[2] Saha, S.N. and Chanda, B.C. "Heat Transfer Study of Fluidised Bed coal Combustion “ - Ind. JI of Power and River Valley Development, Vol 35, Nos. 3\&4, 1985,

[3] Fan, Ling-Shih "Gas -Liquid- Solid Fluidization Engg.", Butterworths Pub. 1989,

[4] Chen, Z., Zheng, C.,Feng,Y., "Distributions of flow regimes and phase holdups in three-phase fluidised beds", Chemical Engineering Science, 50, 2153-2159. 1995.

[5] Grevskott,S., Sannaes, B.H., Dudukovic, M.P.,Hjarbo,K.W.,Svendsen,H.F., "Liquid circulation, bubble size distributions, and solids movement in two-and three-phase bubble columns", Chemical Engineering Science, 51,1703-1713. 1996.

[6] Saha, S.N., "Nitrogen pollution control by using fluidized bed bio reactor", Proc,49th Canadian Chem. Engg. Conf., Saskatoon. Canada, Oct 3-6, 1999

[7] Feng, W.,Wen, J., Fan, J.,Yuan,Q.,Jia, X.,Sun,Y., "Local hydrodynamics of gas- liquidnanoparticles three-phase fluidization", Chemical Engineering Science, 60,6887-6898. 2005

[8] M. van Sint Annaland, N.G. Deen, J.A.M.Kuipers, "Numerical simulation of gas-liquid-solid flows using a combined front tracking and discrete particle method", Chem. Engg. Sc., vol. 60, no. 22, Nov.,2005.

[9] Briens, L.A., Ellis, N., "Hydrodynamics of three-phase fluidized bed systems examined by statistical, fractal, chaos and wavelet analysis methods", Chemical Engineering Science 60,6094-6106. 2005,"

[10] Pamerselvam,R., Savithri, S., Surender, G.D., " CFD Simulation of Hdrodynamics of GasLiquid-Solid Fluidized Bed Reactor” Chem. Engg. Sc., vol.64, no.6, pp 1119-1135. 2009.

[11] Chalermsinsuwan, B., Gidaspow, D., Piumsomboon, P., "Two and three- dimensional CFD modelling of Geldart Aparticles in a thin bubbling fluidised bed: Comparison of turbulence and dispersion coefficients", Chemical Engineering Journal 171, 301-313. 2011.

[12] Khanh-Toan Nguyen, Shyh-Chour Huang, " Simulation of Hydrodynamic Characteristics of Glass Beads in Gas-Liquid-Solid Three Phase Fluidized Beds by Computational Fluid Dynamics", Jl. Of Engg. Tech. and Edu., vol. 8, no. 2, pp. 248-261. June 2011

[13] Saha, S.N. and Gadhewal, R. "Numerical Analysis of 3D Fluidized Bed Coal Combustion", Int. Jl. of Comp. \& Math. Sc., Vol. 4, No.7, July, 2015

[14] Saha, S.N. and Dewangan, G.P. "Modeling and Simulation of Fluidized Bed Catalytic Reactor Regenerator", Int. Jl. of Engg. Tech. Sc. and Res., Vol. 2, No. 9, Sept., 2015,

[15] Saha, S.N. and Dewangan, G.P. "Activated Carbon from Coconut Shell using Fluidized Bed Reactor and its Simulation”, Int. Jl. of Engg. Studies and Tech. App., Vol. 1, No. 11, 2015. 

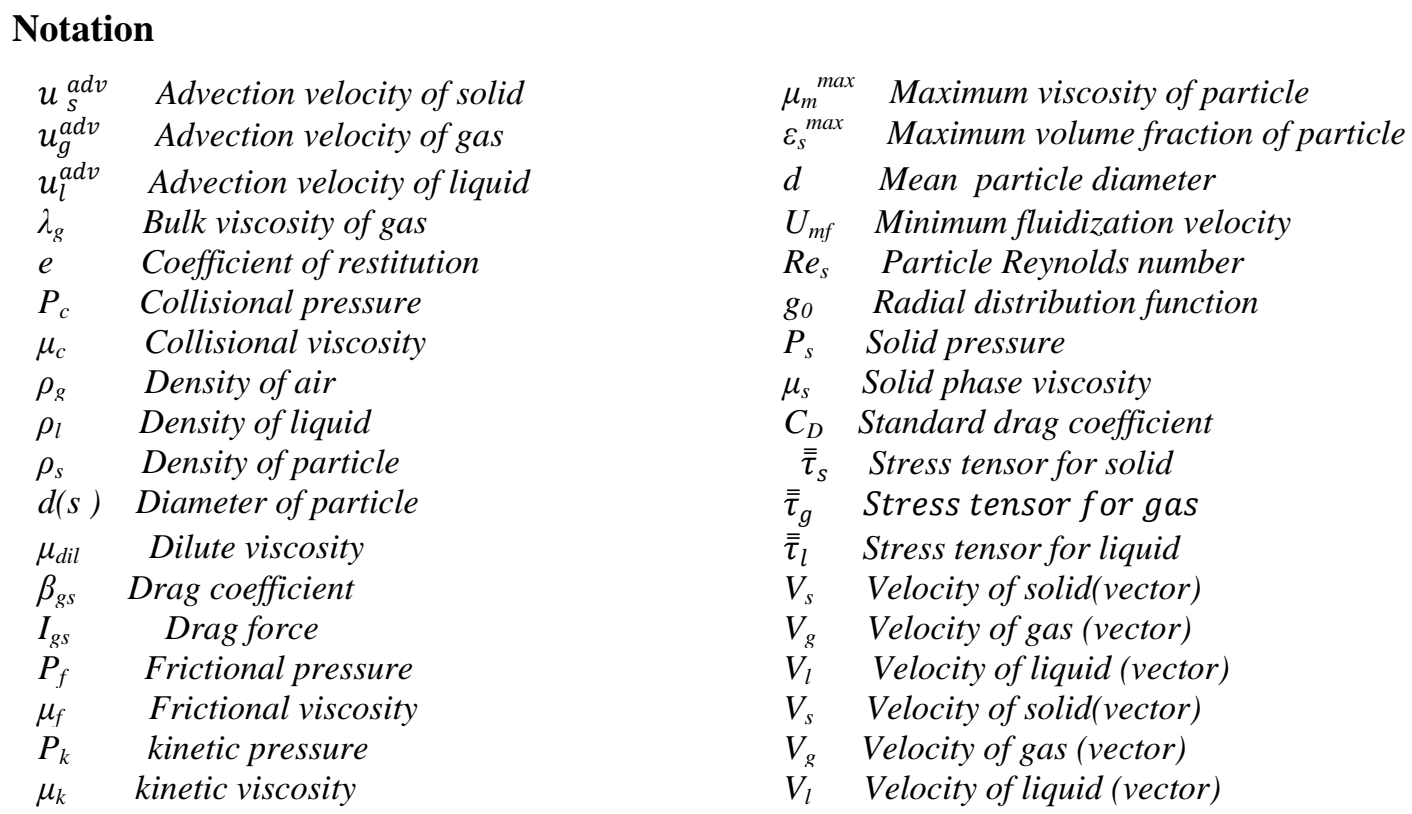

\section{AUTHORS' BIOGRAPHY}

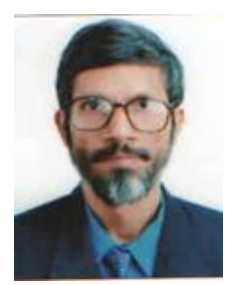

Dr.S.N.Saha, did his B.Ch.E. (1978) and M. Ch. E.(1980) from Jadavpur University, Ph.D. (1992) from BITS Pilani. After having 21/2 years industrial and 11/2 research experience, joined BITS Pilani as faculty member in 1983 and after 13 years teaching as Lecturer and Assistant Professor, joined as Professor of Punjab Government Engineering College in 1996, and worked as Principal. He joined as Professor of Guru Ghasidas University in 2003 and worked as Director and Dean of this University Institute of Technology. He has 64 papers and 4Text books publication in his credit.

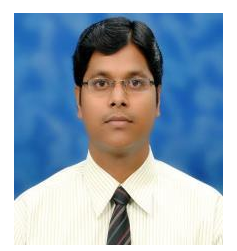

G. P. Dewangan, did his B.E. in Chemical Engineering (2003) from Guru Ghasidas University, and M.Tech (2011) from NIT, Warangal, He has had 1 year industrial, 1 year research experience, has worked as lecturer for 1 year in NIT, Warangal and since 2012 he has been working as Assistant Professor in Guru Ghasidas Vishawavidyalaya Bilaspur.

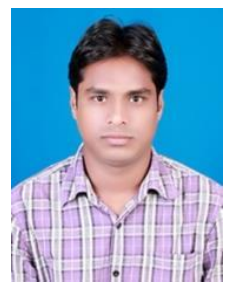

R Gadhewal, did his B.E. in Chemical Engineering (2005) from Guru Ghasidas University, M.Tech (2011) from ISM Dhanbad. He has worked as project fellow of UGC Major research project under Prof. S. N. Saha 11/2 years, presently working as Senior Research Fellow(SRF) DAE-BRNS in IIT, Mandi (H.P). 